\title{
Factors influencing dissolution of carbonaceous materials in liquid Fe- $\mathrm{Mn}$
}

\author{
Hamideh Kaffash $^{1}$ (D) Merete Tangstad $^{1}$
}

Received: 25 July 2019/Revised: 9 January 2020 / Accepted: 13 January 2020/Published online: 17 September 2020

(C) The Author(s) 2020

\begin{abstract}
Carbon dissolution from four types of metallurgical cokes and graphite was investigated by using immersion rods in a resistance furnace to clarify the influence of factors governing the rate of carbon dissolution from carbonaceous materials into Fe-Mn melts at $1550{ }^{\circ} \mathrm{C}$. The factors studied were the microstructure of carbonaceous materials, roughness, porosity and the wettability between carbonaceous materials and the melt. Carbon/metal interface was characterised by scanning electron microscopy accompanied with energy-dispersive X-ray spectrometry to investigate the formation of an ash layer. The results showed that coke $\mathrm{E}$ had the highest dissolution rate. Surface roughness and porosity of the carbonaceous materials seemed to be dominant factors affecting the dissolution rates. Further, crystallite size did not have a significant effect on the dissolution rates. Solid/liquid wettability seemed to affect the initial stage of dissolution reaction. The dissolution mechanism was found to be both mass transfer and interfacial reactions.
\end{abstract}

Keywords Dissolution rate $\cdot$ Carbonaceous material $\cdot$ Wettability $\cdot \mathrm{Fe}-\mathrm{Mn} \cdot$ Carbon dissolution

\section{Introduction}

A variety of carbonaceous materials are being used during the production of ferromanganese, usually in the form of metallurgical coke. Due to the increases in coke prices, high $\mathrm{CO}_{2}$ emissions and high energy consumption which is required for Boudouard reaction, attempts were focused on replacing coke with other reducing agents such as natural gas and carbon dissolved in metal. In previous work by Safarian [1], it was shown that $\mathrm{MnO}$ reduction of slag with carbon dissolved in metal was kinetically more favourable than that with solid carbon. A study by Lee and Kolbeinsen [2] also showed that the dissolution rate of $\mathrm{C}$ into the metal was fast. On the contrary, Skjervheim and Olsen [3] found that the rate of $\mathrm{MnO}$ reduction by solid carbon is about 2.3 times higher than that by dissolved carbon.

There are very little data on the dissolution rate of carbonaceous materials in Mn-containing metals, while the

Hamideh Kaffash

Hamideh.kaffash@ntnu.no

1 Department of Materials Science and Engineering, Norwegian University of Science and Technology, Alfred Getz vei 2, Trondheim 7491, Norway dissolution rate of carbonaceous materials into iron melts has been studied for a long time. The majority of these investigations used graphite in their studies [4-11]. The objective of mentioned studies on carbon dissolution from graphite was to establish an understanding of the mechanism that controls the transfer of carbon from graphite into molten iron. It is generally agreed that the rate of graphite dissolution in liquid iron is controlled by transfer of carbon from graphite into molten iron [5, 11]. Nevertheless, it was found that this mechanism does not necessarily apply to more complex form of carbonaceous material such as petroleum coke, coals and chars and it is assumed to be controlled by more complex mechanisms in addition to liquid side mass transfer [12, 13]. Some studies have attributed the different behaviour of graphite and nongraphitic carbonaceous materials to their respective carbon structure. Wu and Sahajwalla [14], Ohno et al. [15] and Wu [16] found that the larger crystallite size in poorly ordered carbonaceous materials such as coke and coal would increase the carbon dissolution rate and the reason was that, with increasing crystallite size, the ordering in carbon atom arrangement increases and it leads to increased carbon dissociation. In contrast, Cham [17] found no obvious 
effect of crystallite size on the rate of coke dissolution into liquid iron.

Safarian [1] investigated the effect of surface roughness of different graphite on the reduction rate of slags. It was found that the reduction rate increased extensively with increasing surface roughness.

Contradictory observations have been reported in the literature on the effect of carbon porosity on dissolution rate. Deng et al. [18] observed that coke with low porosity has a high rate of dissolution in iron. On the contrary, Mourao et al. [19] reported that coke with high porosity exhibited greater dissolution and further suggested that higher porosity offers more surface area for reaction and its effect seems to be more significant in the initial period of dissolution.

Wetting can affect the contact area between carbon and iron, and good wetting allows liquid to penetrate into pores of the solid or interstitial space between particles to increase the contact area [17].

$\mathrm{Wu}$ and Sahajwalla [4] and Cham [17] found a weak dependence between wettability of cokes and iron and dissolution rate and the reason was that the dissolution rate of cokes and coals showed weak dependence on the contact area. On the other hand, $\mathrm{Wu}$ [16] found a stronger dependence of rate constant on contact area for graphite and coke rather than for coals.

The research focus of this paper is to investigate the effect of carbon microstructure, carbon macrostructure and also liquid/solid wettability on the dissolution rate of different carbonaceous materials in Fe-Mn melts.

\section{Experimental}

Four metallurgical cokes, cokes C, D, E and F which were supplied by industry, and graphite as a reference material were studied in this work. Proximate analysis and ash composition of all carbonaceous materials are shown in Tables 1 and 2, respectively. The total ash content of the graphite is $0.3 \mathrm{wt} \%$, and the ash composition analysis has not been conducted for graphite.

Table 1 Proximate analysis of cokes and charcoal (wt.\%)

\begin{tabular}{llcl}
\hline Component & Fixed carbon & Ash & Volatile matter \\
\hline Coke C & 85.28 & 11.82 & 1.43 \\
Coke D & 89.34 & 9.61 & 1.05 \\
Coke E & 85.57 & 13.68 & 1.35 \\
Coke F & 87.93 & 11.42 & 1.15 \\
Graphite & 98.6 & 0.3 & 0.8 \\
\hline
\end{tabular}

The X-ray diffraction profile of coke samples was obtained using a Philips X'Pert multipurpose X-ray diffraction system (MPD). The wavelength of incident $\mathrm{X}$-ray for $\mathrm{Cu} \mathrm{K} \alpha$ radiation in this study was $0.15409 \mathrm{~nm}$. Powdered coke samples were scanned in the range of $2 \theta$ from $10^{\circ}$ to $50^{\circ}$ with a step of $0.02^{\circ}$. The crystallite size, $L_{\mathrm{c}}$, or stack height and interlayer spacing between aromatic planes of carbon crystallites $d_{002}$ were calculated using the Scherrer equation and Bragg's law.

A caliper was used to measure the volume of the carbon substrate (disc shape), and using a known mass of the substrate, the apparent density was calculated. The absolute density was determined using a Micromeritics Accupyc II 1340 helium pycnometer at University of New South Wales. The helium is able to penetrate the particle and fill the pores. A Keyence VK-X250 laser microscope was used to measure the surface roughness of carbonaceous materials. The laser system can create three-dimensional surface images which capture colour and topographical information and are used to analyse form and roughness parameters.

The wettability of cokes and graphite with Fe-85 wt.\% Mn was determined using a graphite furnace shown in Fig. 1. The furnace was designed with high cooling rate which allowed the samples to be quenched to a temperature below the melting point quickly after experiments. The metal/carbon assembly was placed on a graphite stage and slid into the hot zone of the furnace. Masses of the substrate $(\sim 0.2 \mathrm{~g})$ and metal $(\sim 0.37 \mathrm{~g})$ were recorded prior to experiment. The furnace chamber was evacuated initially and then backfilled with the Ar with a flow rate of 1.5 $\mathrm{L} / \mathrm{min}$ until the end of the test. The temperature increased at a heating rate of $25{ }^{\circ} \mathrm{C} / \mathrm{min}$ to $1550{ }^{\circ} \mathrm{C}$ and then kept for $30 \mathrm{~min}$ to maintain isothermal conditions. The melting of metal was marked as the beginning of contact time. A Sony DCR-TRV18E digital video camera was used to record image sequences during the wetting experiments. This camera gives images at a resolution of $720 \times 576$ pixels. A pair of Vivitar zoom lenses (one $4 \times$, one $1 \times$ ) are screwed onto the camera lens to provide the correct focal length for viewing within the furnace. ImageJ software was used to determine the contact angle by estimating an average of two sides when the difference is within acceptable limits for the method used (Fig. 2).

A vertical tube furnace was used for heating the samples in an inert $\mathrm{Ar}$ atmosphere. The heat was supplied by a resistant graphite element to heat the samples. The carbon rods that were used as carbon source to dissolve into the alloy were fixed with a Mo wire to an $\mathrm{Al}_{2} \mathrm{O}_{3}$ tube. The furnace was evacuated by vacuum before it was filled with argon gas before start. All the experiments were run under an atmosphere of argon gas of grade 4.0 having a minimum purity of $99.99 \%$, at a gas flow of $2.5 \mathrm{~L} / \mathrm{min}$. 
Table 2 Ash analysis of cokes and charcoal in dry basis (wt.\%)

\begin{tabular}{lllllllll}
\hline Carbonaceous material & $\mathrm{SiO}_{2}$ & $\mathrm{Al}_{2} \mathrm{O}_{3}$ & $\mathrm{Fe}_{2} \mathrm{O}_{3}$ & $\mathrm{CaO}$ & $\mathrm{MgO}$ & $\mathrm{MnO}$ & $\mathrm{K}_{2} \mathrm{O}$ & $\mathrm{S}$ \\
\hline Coke C & 6.97 & 3.07 & 0.87 & 0.66 & 0.24 & 0.08 & 0.03 & 0.44 \\
Coke D & 4.22 & 2.84 & 0.83 & 0.42 & 0.19 & 0.1 & 0.22 & 0.50 \\
Coke E & 7.35 & 3.96 & 0.95 & 0.43 & 0.09 & 0.01 & 0.11 & 0.63 \\
Coke F & 6.29 & 2.87 & 0.68 & 0.39 & 0.18 & 0.01 & 0.23 & 0.50 \\
\hline
\end{tabular}

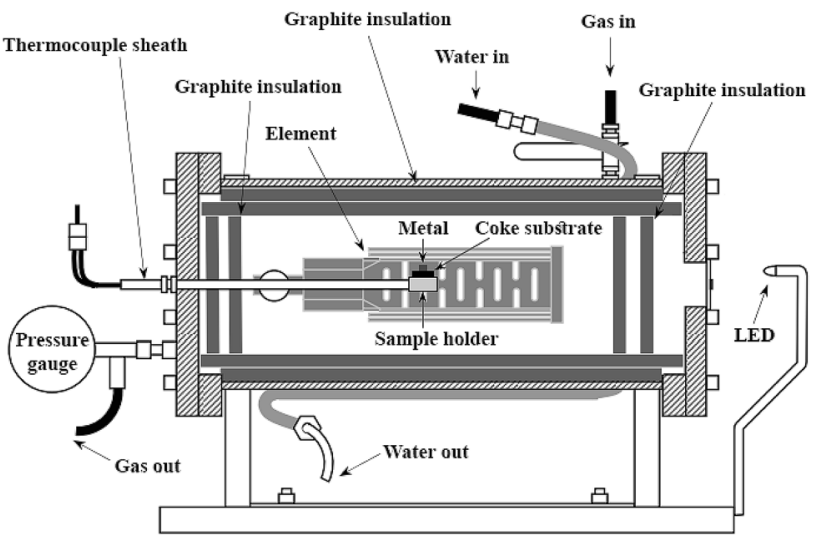

Fig. 1 Schematic diagram of sessile drop furnace used for wetting experiments

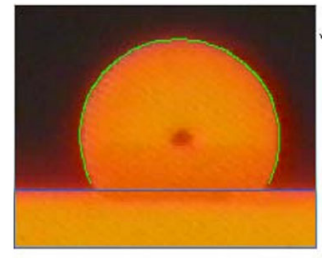

Left contact angle $=128.25^{\circ}$

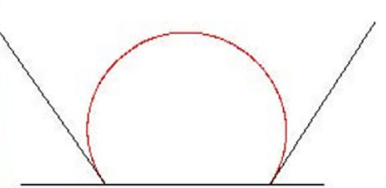

Right contact angle $=126.00^{\circ}$
Fig. 2 Sample program output for captured image angle analysis

The alumina crucible which was used for all melting experiments had an outer diameter of $40 \mathrm{~mm}$ and a height of $60 \mathrm{~mm}$. Two thermocouples, one B-type for controlling the furnace and one C-type for temperature measurement, were used during the experiments. Schematic illustration for furnace setup used in the measurement of carbon dissolution rate into different $\mathrm{Fe}-\mathrm{Mn}$ alloys from graphite is shown in Fig. 3.

Experiments were conducted at $1550{ }^{\circ} \mathrm{C}$. The furnace was heated to the desired temperature at a rate of $20{ }^{\circ} \mathrm{C} /$ min under continuous argon purging. After the metal was melted, time was allowed for thermal stabilisation of the bath for 30 min before any carbon addition. Carbon rods were then immersed in the liquid metal for specified time. It is worth mentioning that the immersion rod method was

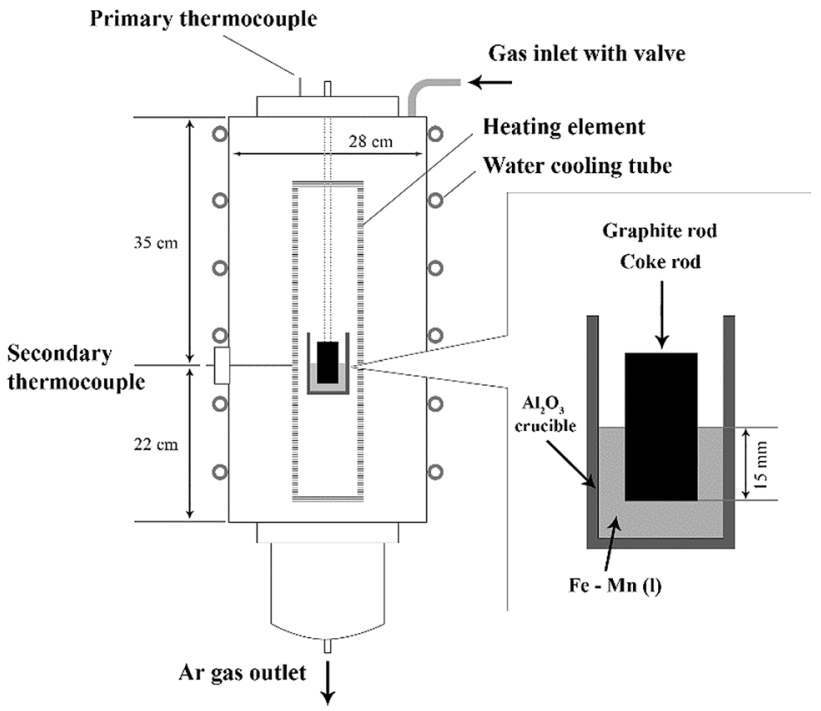

Fig. 3 Apparatus for carbon dissolution rate measurement using carbon rods

chosen because then the mass transport phenomena could be determined by the change of geometric size or mass of the carbon rod before and after the dissolution experiment. The carbon rods were preheated to the requisite temperature and then dipped into the metal melt by holding them over the bath for a predetermined time period. This was done to avoid boiling in the bath due to the immersion of cold sample containing volatiles. Carbon samples were drawn from the bath after the predetermined time interval, and the crucible with the molten metal was pulled out from the bottom of the furnace. The amount of carbon as a function of time was determined by chemical analysis of the metal samples (dissolution experiments) using combustion infrared technique (LECO CS-200, St. Joseph, USA) measured by SINTEF Molab. A scanning electron microscope (SEM), Hitachi S-3400, accompanied with energy-dispersive spectrometer was used to study the interface between coke and metal after sessile drop experiment. 

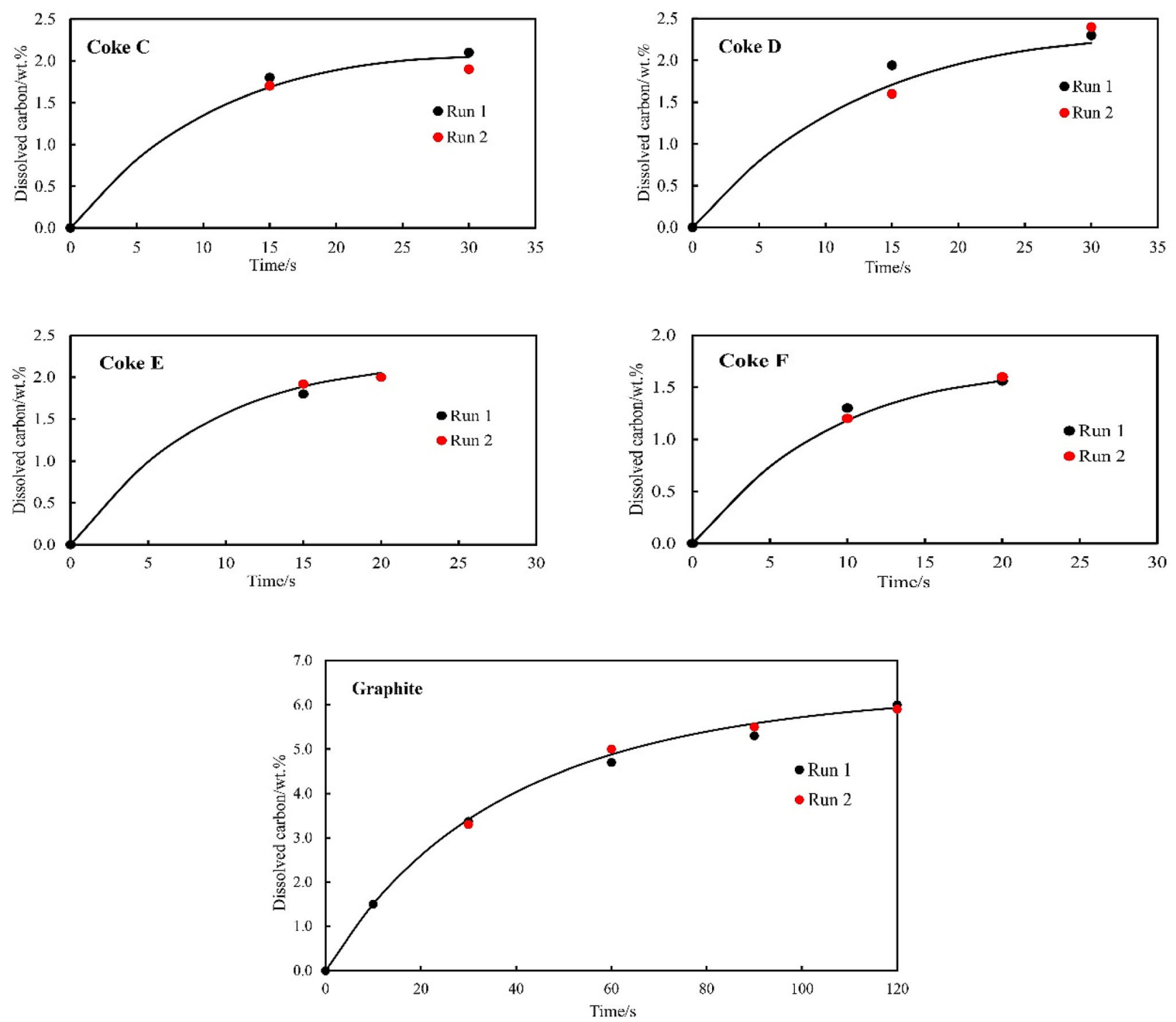

Fig. 4 Carbon concentration of bath against time for different forms of carbon at $1550{ }^{\circ} \mathrm{C}$

\section{Results and discussion}

The carbon dissolution rates by liquid Fe- 85 wt.\% Mn over time for the four cokes and graphite are depicted in Fig. 4. It shows that the rates of carbon dissolution varied with the carbonaceous material used. It should be noted that the area of the graphite rod is somewhat larger than those of the other materials. For the carbonaceous materials used in this study, the final carbon content of each dissolution run did not reach saturation due to the limitation of the size of carbonaceous materials used. The solid lines are obtained from the modelling using a first-order dissolution rate [Eq. (1)], and an acceptable fit can be seen between the model and measured carbon content in both runs.
The first-order reaction rate for the carbon dissolution rate $\mathrm{d} C / \mathrm{d} t$ given in Eq. (1) is generally accepted by several researchers [4-10].

$\frac{\mathrm{d} C}{\mathrm{~d} t}=\frac{k_{t}}{A} V\left(C_{\mathrm{s}}-C_{t}\right)$

where $C_{\mathrm{s}}$ and $C_{t}$ are the saturation carbon solubility and the carbon content at time $t$, respectively; $A$ is the interfacial contact area, $\mathrm{cm}^{2} ; V$ is the volume of molten metal, $\mathrm{cm}^{3}$; and $k_{t}$ is the first-order overall dissolution rate constant, $\mathrm{cm} / \mathrm{s}$.

Saturation carbon content of the metal as a function of temperature and iron and manganese contents can be calculated from the following correlation proposed by Sandvik and Tuset [20]. 
$\lg C_{\mathrm{s}}=(1.005-478 / T)+0.147 w_{\mathrm{Mn}} /\left(w_{\mathrm{Mn}}+w_{\mathrm{Fe}}\right)$

where $T$ is temperature; and $w_{\mathrm{Mn}}$ and $w_{\mathrm{Fe}}$ are the mass percent of manganese and iron in metal, respectively.

This gives a saturation level of $7.58 \mathrm{wt} . \% \mathrm{C}$ at $1823 \mathrm{~K}$ for the given alloy. The interfacial area in Eq. (1) is calculated from the average dimensions of the solid rod before and after its immersion. As the dissolution progresses, the diameter of the samples continuously reduces and so does the surface area. In this study, contrary to other reported studies in this area $[10,18]$, changes in surface area of carbonaceous materials were taken into account in the model.

$k_{t}$ is determined from the negative slope of a plot of $-k_{t} t=V / A \ln \left[\left(C_{\mathrm{s}}-C_{t}\right) /\left(C_{\mathrm{s}}-C_{0}\right)\right]$ versus time, as shown in Fig. 5, where $C_{0}$ is the carbon content at time 0. From this plot, the corresponding overall rate constants were determined, as shown in Fig. 6.

A good linear relationship between $-k_{t}=V / A$ $\ln \left[\left(C_{\mathrm{s}}-C_{t}\right) /\left(C_{\mathrm{s}}-C_{0}\right)\right]$ against time can be clearly discerned from Fig. 5. Overall dissolution rate constant is a combination the rate constant for the chemical reaction at the interface $k_{\mathrm{r}}$ and mass transfer coefficient $k_{\mathrm{m}}$, as shown in Eq. (3) [21].

$\frac{1}{k_{t}}=\frac{1}{k_{\mathrm{r}}}+\frac{100 f}{k_{\mathrm{m}} \rho K_{\mathrm{r}}}$

$K_{\mathrm{r}}=\frac{a_{\mathrm{C}}^{\mathrm{sat}}}{a_{(\mathrm{C})}}$

where $f$ is the carbon activity coefficient at the liquid side of the interface; $\rho$ is the density of liquid; $K_{\mathrm{r}}$ is the equilibrium constant for the dissolution reaction; $a_{(\mathrm{C})}$ is activity of carbon in carbonaceous material; and $a_{\mathrm{C}}^{\text {sat }}$ is activity of carbon in liquid metal. Since $k_{\mathrm{m}}$ and $k_{\mathrm{r}}$ are both unknown, it is not possible to identify the dissolution mechanism, but it is possible to investigate the influencing factors on each parameter in Eq. (3) and thus predict the most likely dissolution mechanism.

\subsection{Effect of ash}

Ash in carbonaceous materials would accumulate at the interface and become physical barriers at the interface, reducing contact area available for further carbon dissolution [21]. It is important to note that $k_{t}$ for cokes was higher than that for graphite which was quite unexpected as other researchers have generally reported coke dissolution to be rather slow when compared to graphite dissolution [19, 22]. One of the reasons may be due to the fact that all of our experiments were done within $1 \mathrm{~min}$ and as shown in Fig. 6, the ash layers were not yet formed to act as barrier for dissolution. Figure $7 \mathrm{a}, \mathrm{b}$ shows the coke/metal interface after 15 and $30 \mathrm{~s}$, respectively. It can be seen that white particles which mostly consist of $\mathrm{Al}_{2} \mathrm{O}_{3}$ and $\mathrm{SiO}_{2}$ exist in the interface, but it is difficult to distinguish the minerals which were in the coke before dissolution reaction and the minerals formed after dissolution, and these minerals had not formed layers that can retard the dissolution rate. It is worth mentioning that coke $\mathrm{E}$ had the highest amount of ash (13 wt.\%).

\subsection{Effect of carbon microstructure}

As shown in Fig. 8, the graphitisation given by $L_{\mathrm{c}}$ is different for various carbonaceous materials at $1550{ }^{\circ} \mathrm{C}$. Figure 9 shows the carbon crystallite size, as determined using Scherrer's equation, for all cokes and their dissolution rates in $\mathrm{Fe}-85$ wt. $\% \mathrm{Mn}$ at $1550{ }^{\circ} \mathrm{C}$ before contact with liquid metal. It can be seen from Fig. 9 that there was little difference in $L_{\mathrm{c}}$ between four coke samples and therefore the high overall dissolution of certain cokes cannot be explained on the basis of crystallite size. It is in agreement with findings of Cham [17] who found no correlation between the carbon crystallite size of cokes (with similar crystallite sizes) and their dissolution rates in molten iron. It is, however, in contradiction with findings of $\mathrm{Wu}$ et al. $[14,16]$ who reported a link between structural ordering and dissolution rates of non-graphitic carbonaceous materials.

Structure of carbon may affect $k_{\mathrm{r}}$ and to a minor extent $K_{\mathrm{r}}$ and $C_{\text {sat }} . C_{\text {sat }}$ is the equilibrium carbon content with the solid and varies with $K_{\mathrm{r}}$ and thus the solid structure. This is because $k_{\mathrm{r}}$ describes the dissociation reaction rate of carbon atoms from solid lattice into the metal. The dissociation process includes the ruptures of atomic bonding type, and the bonding strength is determined by the solid structure. $K_{\mathrm{r}}$ is related to the free energy change which depends on the solid structure. Different carbonaceous materials such as graphite, charcoal, cokes and diamond are carbon of different structures, and they have different $K_{\mathrm{r}}$ [21]. The mass transfer limiting mechanism is supported by the effect of carbon microstructure on dissolution rate.

\subsection{Effect of carbon macrostructure}

In this study, the uniformity of the surface is supported by the average roughness $R a$. The average roughness is the main height as calculated over the entire measured area. Table 3 shows $R a$ for all carbonaceous materials. The average values are given from three measurements and for some samples from four measurements and show a standard deviation of $11 \%$ or less. As Table 4 shows, coke E has the roughest surface and graphite has the smoothest surface. 

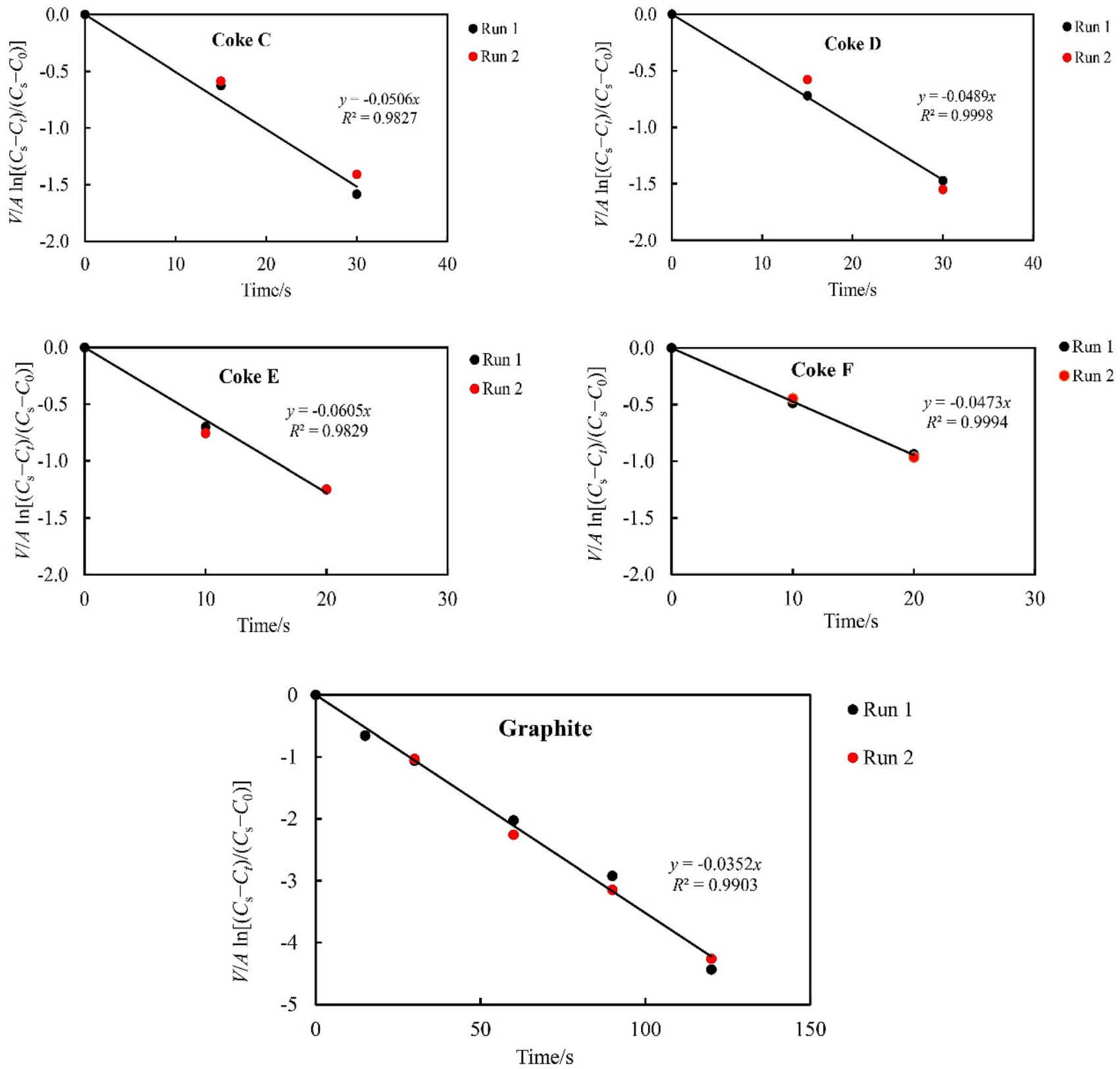

- Run 1

- Run 2

Fig. 5 Sample plots on $-k_{t}=V / A\left[\ln \left(C_{\mathrm{s}}-C_{t}\right) /\left(C_{\mathrm{s}}-C_{0}\right)\right]$ against time for different carbonaceous materials. $R^{2}$ Correlation coefficient

The porosity of different carbonaceous materials measured by pycnometry is shown in Table 4. Three replicates were done for each sample. As Table 4 shows, charcoal has the highest porosity and graphite has the lowest porosity. Among cokes, coke $\mathrm{E}$ has the highest porosity and coke $\mathrm{C}$ has the lowest porosity.

In this study, roughness and porosity of carbonaceous materials follow the same trend. Table 5 shows the results of roughness and porosity of all carbonaceous materials and also their dissolution rate constant in Fe-85 wt.\% Mn at
$1550{ }^{\circ} \mathrm{C}$. It can be seen from Fig. 10 that among cokes, with increasing roughness and porosity, the dissolution rate showed an increasing trend. Thus, a correlation can be seen between macrostructure of cokes and their overall dissolution rate in $\mathrm{Fe}-85 \mathrm{wt} . \% \mathrm{Mn}$. The roughness and porosity of cokes are coke $\mathrm{E}>$ coke $\mathrm{D}>$ coke $\mathrm{F}>$ coke $\mathrm{C}$, while the dissolution rates of cokes are coke $\mathrm{E}>$ coke $\mathrm{C}>$ coke $\mathrm{D}>$ coke $\mathrm{F}$. This is in agreement with findings of Mourao et al. [19] who reported that cokes with high porosity exhibit higher dissolution rate and further suggested that 


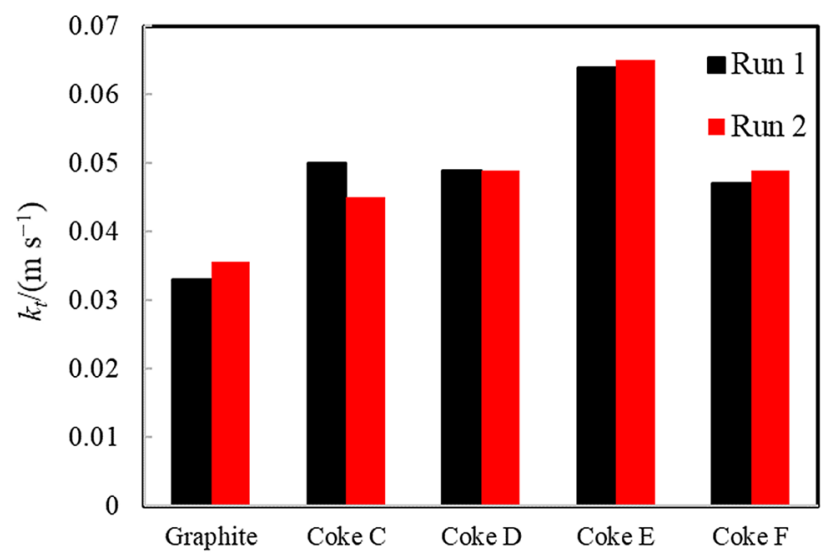

Fig. $6 k_{t}$ for various carbonaceous materials at $1550{ }^{\circ} \mathrm{C}$

higher porosity offers more surface area for reaction and its effect seems to be more significant in the initial stage because at the later stage, the liquid metal may get trapped in the pores and tend to get saturated by carbon. Upon comparing graphite and cokes, the same explanation could be used for graphite as well. Graphite with the lowest porosity and surface roughness showed the lowest dissolution rate.
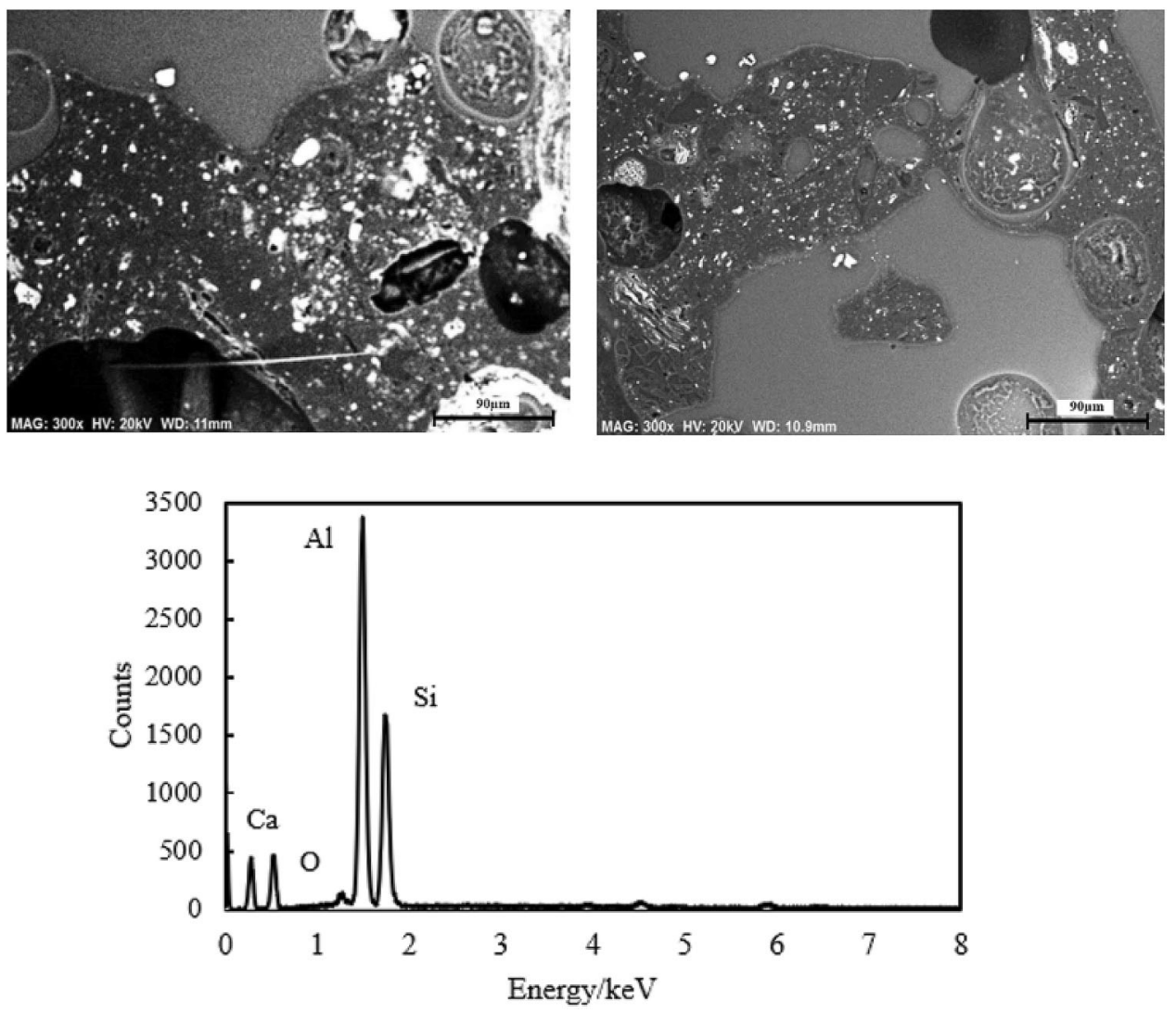

Fig. 7 SEM image of coke E after $15 \mathrm{~s} \mathrm{(a)} \mathrm{and} 30 \mathrm{~s}$ (b) immersion in Fe-85 wt.\% Mn and energy-dispersive X-ray spectrometry analysis of a white particle (c) 


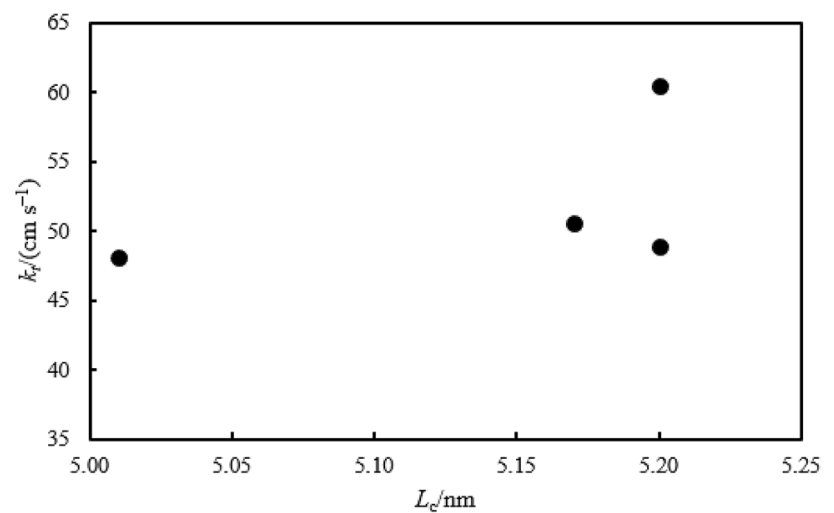

Fig. $9 L_{\mathrm{c}}$ values versus $k_{t}$ at $1550{ }^{\circ} \mathrm{C}$ for cokes

to graphite at the initial stage might be owing to its good wettability with the metal at the initial stage of dissolution. Graphite contact angles did not change significantly and remained more or less constant during wetting. Good wetting of cokes with Fe-85 wt.\% Mn confirms non-existence of blocking ash layer at the initial stage of dissolution.

Figure 12 shows the relationship between initial contact angle of different cokes and their dissolution rate in $\mathrm{Fe}-85$ wt.\% Mn at $1550{ }^{\circ} \mathrm{C}$. An increasing trend can be seen between initial contact angle and the dissolution rate. However, the $R^{2}$ value is not so high. It is worth
Table 5 Roughness, porosity and dissolution rate constant for different carbonaceous materials

\begin{tabular}{lccc}
\hline Carbonaceous material & $R a / \mu \mathrm{m}$ & Porosity $/ \%$ & $k_{t} /\left(\mathrm{cm} \mathrm{s}^{-1}\right)$ \\
\hline Graphite & 8 & 6 & $35.2 \times 10^{-3}$ \\
Coke C & 63 & 44 & $50.6 \times 10^{-3}$ \\
Coke D & 73 & 48 & $48.9 \times 10^{-3}$ \\
Coke E & 97 & 55 & $60.5 \times 10^{-3}$ \\
Coke F & 67 & 46 & $48.1 \times 10^{-3}$ \\
\hline
\end{tabular}

mentioning that the difference in initial contact angles is just within $5^{\circ}$ and thus the difference between the dissolution rate cannot be explained on the basis of initial contact angles.

In this study, we have not investigated the dissolution mechanism, but from the factors influencing the dissolution rate, we would guess what the dissolution mechanism could be. If the mass transfer was the only dissolution mechanism, all the carbonaceous materials should have the same dissolution rate which is not correct in our case. Furthermore, since the microstructure and macrostructure of carbonaceous materials and carbon/metal wettability affect the dissolution rate, it can be concluded that interfacial reactions may also be a rate determining step. Thus, the dissolution mechanism in this study is mixture of mass transfer and interfacial reaction.

Table 3 Roughness of carbonaceous materials

\begin{tabular}{|c|c|c|c|c|c|c|c|}
\hline \multirow[t]{2}{*}{ Carbonaceous material } & \multicolumn{4}{|l|}{$R a / \mu \mathrm{m}$} & \multirow[t]{2}{*}{ Average $/ \mu \mathrm{m}$} & \multirow[t]{2}{*}{ Standard deviation $/ \mu \mathrm{m}$} & \multirow[t]{2}{*}{ Standard deviation $/ \%$} \\
\hline & Run 1 & Run 2 & Run 3 & Run 4 & & & \\
\hline Graphite & 9 & 10 & 6 & 7 & 8 & 1.58 & 16 \\
\hline Coke $\mathrm{C}$ & 65 & 62 & 63 & - & 63 & 1.29 & 2 \\
\hline Coke D & 71 & 69 & 79 & - & 73 & 4.32 & 5.5 \\
\hline Coke E & 97 & 95 & 98 & 100 & 97 & 1.87 & 2 \\
\hline Coke F & 67 & 66 & 68 & 66 & 67 & 0.86 & 1.2 \\
\hline
\end{tabular}

Table 4 Porosity determined by pycnometry

\begin{tabular}{|c|c|c|c|c|c|}
\hline \multirow[t]{2}{*}{ Carbonaceous material } & \multicolumn{2}{|l|}{ Absolute density } & \multicolumn{2}{|l|}{ Apparent density } & \multirow[t]{2}{*}{ Porosity/\% } \\
\hline & Value/( $\left(\mathrm{g} \mathrm{cm}^{-3}\right)$ & $\overline{\text { Standard deviation } / \%}$ & Value/( $\left.\mathrm{g} \mathrm{cm}^{-3}\right)$ & $\overline{\text { Standard deviation/\% }}$ & \\
\hline Graphite & 2.05 & \pm 3 & 1.92 & \pm 2 & 6 \\
\hline Coke C & 1.81 & \pm 10 & 1.01 & \pm 15 & 44 \\
\hline Coke D & 1.85 & \pm 18 & 0.96 & \pm 12 & 48 \\
\hline Coke E & 1.93 & \pm 12 & 0.85 & \pm 12 & 55 \\
\hline Coke F & 1.87 & \pm 11 & 1.009 & \pm 9 & 46 \\
\hline
\end{tabular}




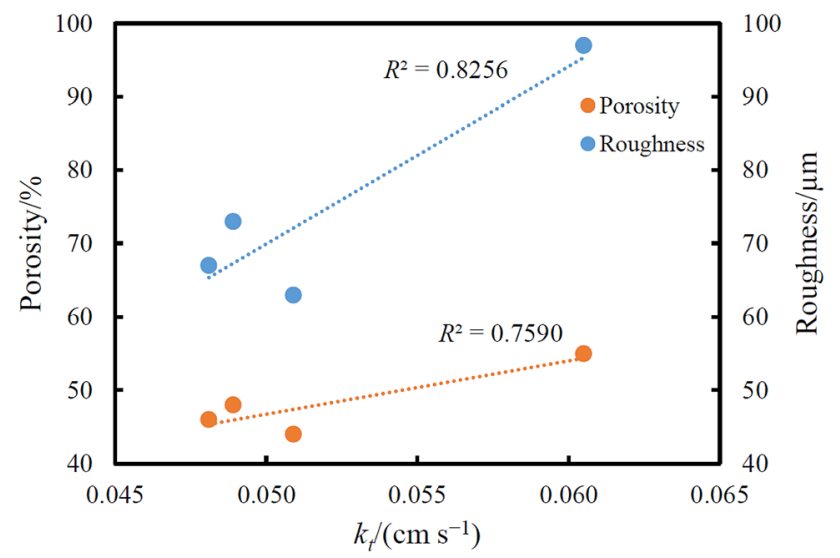

Fig. 10 Relationship between roughness and porosity of cokes and their overall dissolution rate in $\mathrm{Fe}-85 \mathrm{wt} . \% \mathrm{Mn}$ at $1550{ }^{\circ} \mathrm{C}$
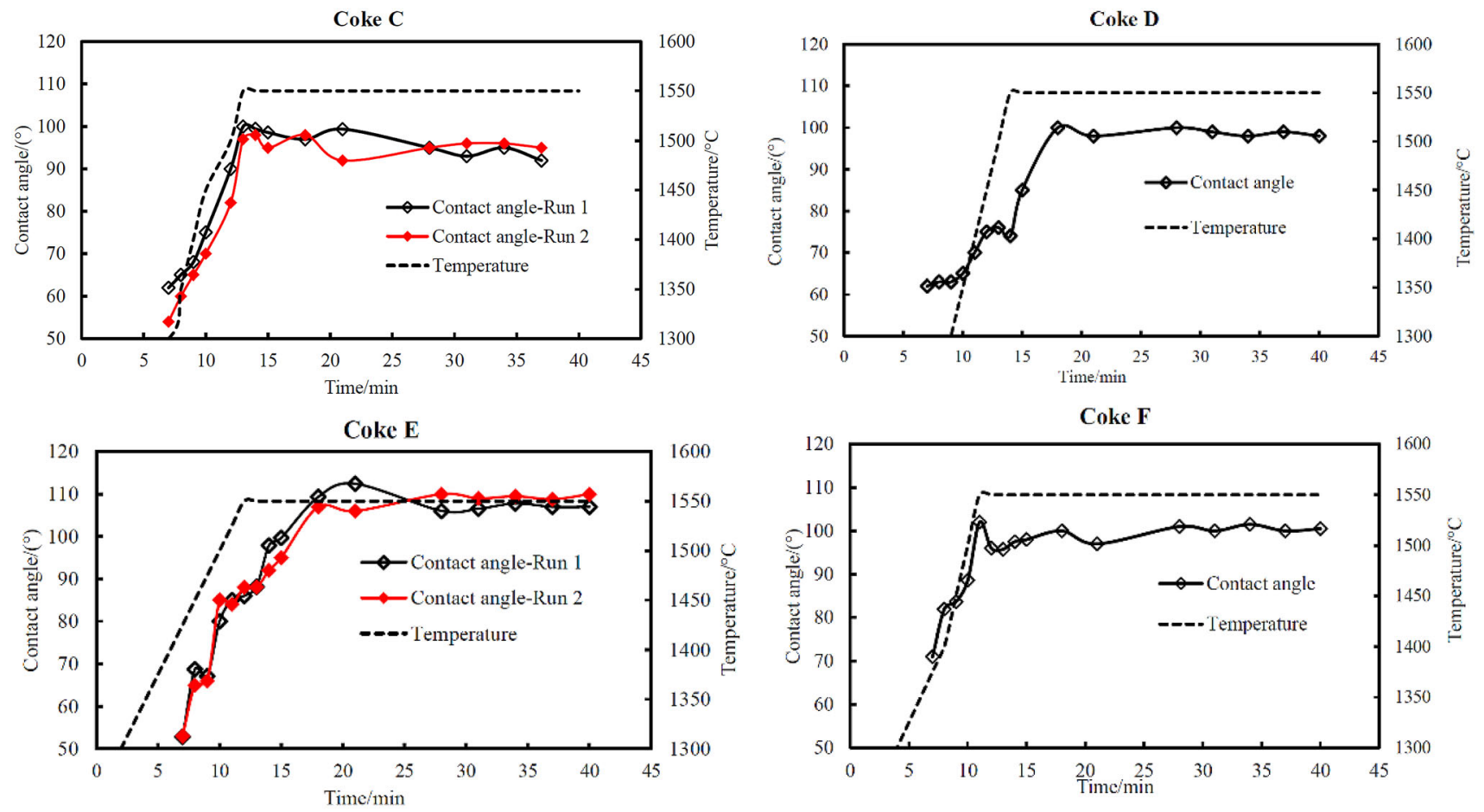

Graphite

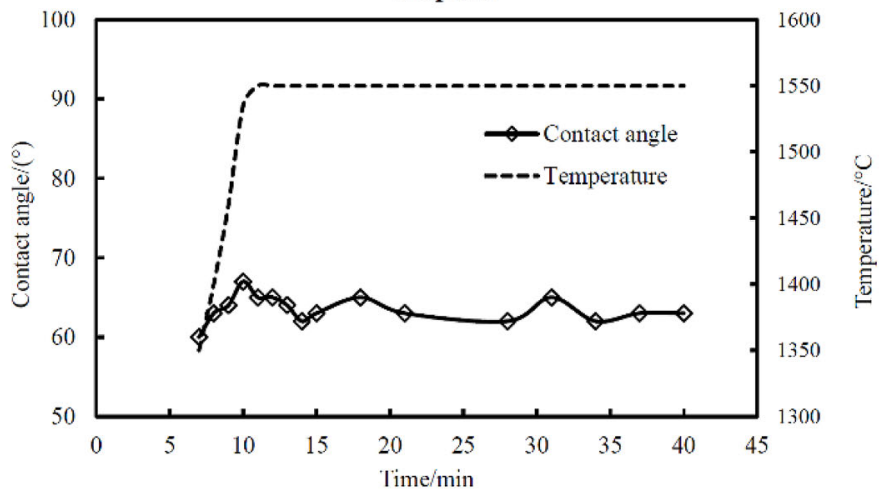

Fig. 11 Dynamic contact angle measurements for cokes and graphite with Fe-85 wt.\% Mn vs. time and temperature
Table 6 Contact angle and dissolution rate of different cokes at $1550{ }^{\circ} \mathrm{C}$

\begin{tabular}{lll}
\hline Carbonaceous materials & Initial contact angle $/\left({ }^{\circ}\right)$ & $k_{t} /\left(\mathrm{cm} \mathrm{s}^{-1}\right)$ \\
\hline Coke C & 60 & $50.6 \times 10^{-3}$ \\
Coke D & 62 & $48.9 \times 10^{-3}$ \\
Coke E & 65 & $60.5 \times 10^{-3}$ \\
Coke F & 62 & $48.1 \times 10^{-3}$ \\
Graphite & 61 & $35.2 \times 10^{-3}$ \\
\hline
\end{tabular}




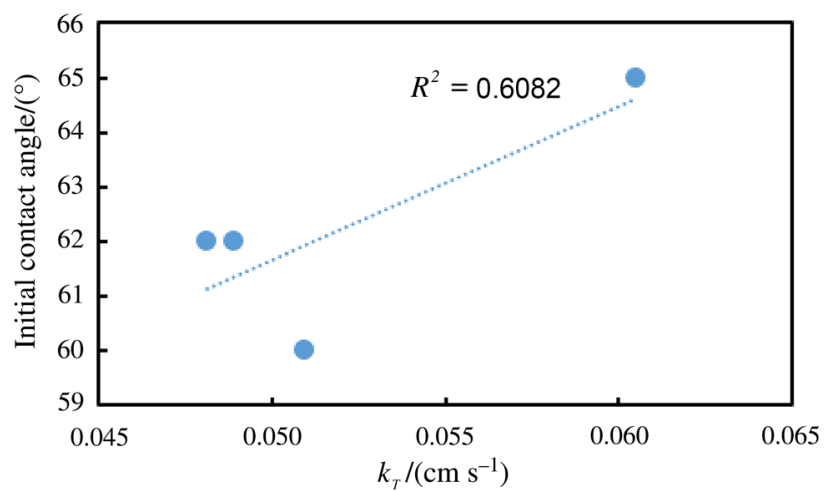

Fig. 12 Relationship between initial and final contact angles and dissolution rate for different coke samples and dissolution rates in $\mathrm{Fe}$ 85 wt. $\% \mathrm{Mn}$ at $1550{ }^{\circ} \mathrm{C}$

\section{Conclusions}

For the cokes, there were no obvious effects of carbon structure on the rate of carbon dissolution. The crystallite sizes of the four cokes were similar and therefore the effect of $L_{\mathrm{c}}$ could not be established. Among different types of carbonaceous materials, carbon dissolution rates generally increase as carbon ordering increases, but in the present study, graphite had higher crystallite size but lower dissolution rate.

Porosity and roughness of the cokes seemed to be a dominant factor affecting the dissolution rates, and higher roughness and porosity contributed to higher dissolution rate. It was also confirmed by comparing two types of carbonaceous materials (graphite and cokes).

Cokes showed wetting behaviour with contact angles ranging between $60^{\circ}$ and $65^{\circ}$ at the time of metal melting. Good wetting of cokes with metal at the initial stage of dissolution might be the reason for higher dissolution rate of cokes. Among cokes, a significant trend could not be found between wettability and dissolution rates at the initial stage of dissolution.

Microstructure of carbonaceous materials did not affect the dissolution rate, and this supports the rate-limiting step to be the carbon mass transfer in metal. Liquid/solid wettability and macrostructure of carbonaceous materials affected the dissolution rate, and it supports the rate-limiting step to be interfacial reactions. Thus, the dissolution mechanism is found to be a combination of both mass transfer and interfacial reactions.

Acknowledgements This work was funded by Department of Materials Science and Engineering of Norwegian University of Science and Technology (NTNU) in cooperation with the SFI Metal production (NRC 237738).

Open Access This article is licensed under a Creative Commons Attribution 4.0 International License, which permits use, sharing, adaptation, distribution and reproduction in any medium or format, as long as you give appropriate credit to the original author(s) and the source, provide a link to the Creative Commons licence, and indicate if changes were made. The images or other third party material in this article are included in the article's Creative Commons licence, unless indicated otherwise in a credit line to the material. If material is not included in the article's Creative Commons licence and your intended use is not permitted by statutory regulation or exceeds the permitted use, you will need to obtain permission directly from the copyright holder. To view a copy of this licence, visit http://creativecommons. org/licenses/by/4.0/.

Funding Open Access funding provided by NTNU Norwegian University of Science and Technology (incl St. Olavs Hospital Trondheim University Hospital).

\section{References}

[1] J. Safarian, Kinetics and mechanisms of reduction of MnOcontaining silicate slags by selected forms of carbonaceous materials, Norwegian University of Science and Technology, Trondheim, Norway, 2007.

[2] Y.E. Lee, L. Kolbeinsen, ISIJ Int. 45 (2005) 1282-1290.

[3] T.A. Skjervheim, S.E. Olsen, in: 51st Electric Furnace Conference Proceedings, Washington, USA, 1993, pp. 137-144.

[4] C. Wu, V. Sahajwalla, Metall. Mater. Trans. B 31 (2000) 243-251.

[5] O. Dahlke, O. Knacke, Steel Res. Int. 26 (1955) 373-378.

[6] R.G. Olsson, V. Koump, T.F. Perzak, Trans. AIME 236 (1966) 426-429.

[7] M. Kosaka, S. Minowa, Tetsu-to-Hagane 53 (1967) 983-997.

[8] Y. Shigeno, M. Tokuda, M. Ohtani, Trans. Jpn. Inst. Met. 26 (1985) 33-43.

[9] R. Khanna, F. McCarthy, H. Sun, V. Sahajwalla, N. Simento, Metall. Mater. Trans. B 36 (2005) 719-729.

[10] S.T. Cham, R. Sakurovs, H. Sun, V. Sahajwalla, ISIJ Int. 46 (2006) 652-659.

[11] D. Bandyopadhyay, S.D. Singh, D. Sanyal, K.K. Singh, K.N. Singh, Chem. Eng. J. 94 (2003) 79-92.

[12] H. Sun, Metall. Mater. Trans. B 36 (2005) 893-894.

[13] Z. Zhang, J. Zhang, K. Jiao, H. Song, Z. Liu, in: T. Jiang, J.Y. Hwang, R.F. Gerardo, F. Alvear, O. Yücel, X. Mao, H.Y. Sohn, N. Ma, P.J. Mackey, P. Battle (Eds.), 6th International Symposium on High-Temperature Metallurgical Processing, The Minerals, Metals and Materials Society, USA, 2015, pp. 147-153.

[14] C. Wu, V. Sahajwalla, Metall. Mater. Trans. B 31 (2000) $215-216$.

[15] K.I. Ohno, T. Maeda, K. Nishioka, M. Shimizu, ISIJ Int. 50 (2010) 53-58

[16] C. Wu, Fundamental investigation of molten iron/carbon interactions in direct ironmaking, University of New South Wales, Sydney, Australia, 1998.

[17] S.T. Cham, Investigating factors that influence carbon dissolution from coke into molten iron, University of New South Wales, Sydney, Australia, 2007.

[18] Y. Deng, J.L. Zhang, K.X. Jiao, ISIJ Int. 58 (2018) 815-822.

[19] M.B. Mourao, G.G. Krishna Murthy, J.F. Elliott, Metall. Mater. Trans. B 24 (1993) 629-637.

[20] J. Sandvik, J.K. Tuset, The solubility of carbon in ferrosilicomanganese at $1330-1360^{\circ} \mathrm{C}$, SINTEF Report No. 340420, 1970.

[21] H. Sun, ISIJ Int. 45 (2005) 1482-1488.

[22] H. Gudenau, D. Senk, A. Babich, C. Froehling, in: International BF lower zone symposium, Wollongang, Australia, 2002, pp. 1-12. 